\title{
Dynamics of the ideal self
}

\author{
Richard Boyatzis and Udayan Dhar \\ Organizational Behavior, Case Western Reserve University, Cleveland, Ohio, USA
}

\begin{abstract}
Purpose - The ideal self has had a place in management literature in recent years with reference to identity and role change. However, except for a JMD article in 2006, there has been little theorizing on the ideal self, which is often treated as a static construct. The purpose of this article is to update and refine the concept and explain the dynamic nature of the construct.

Design/methodology/approach - This conceptual paper is based on a review of the recent management and psychology literature related to the ideal self and its components.

Findings - The authors propose a dynamic theory of the emerging ideal self and delineate how its components evolve over time.

Research limitations/implications - The ideal self, or one's personal vision, is a major motivator of learning and change and the sustainability of such efforts. The time dynamic theory would encourage and guide longitudinal research using better variables and measures as well as help in conceptualizing the role of socialization, social identity and life/career stages.

Practical implications - With a better theory of the ideal self, trainers, consultants, coaches and teachers can help people update their deep sense of purpose and the sustaining driver of learning and change the ideal self. It could help people and organizations address a major determinant of engagement.

Originality/value - This theory offers a temporal understanding of how the ideal self can motivate learning and change at different life and career eras, which can help in designing future research on identity-related transitions.
\end{abstract}

Keywords Ideal self, Personal vision, Identity, Purpose, Possible selves, Liminality, Career development Paper type Conceptual paper

\section{Introduction}

In an increasingly secular world that values individual agency, traditional sources of meaning or purpose, such as religious beliefs, community traditions or family values, do not have the same relevance as before (Cates, 2015). This is manifest in low employee engagement (Harter, 2020), identity conflict (Gibson et al., 2020) and concerns around mental health issues (Stolzer, 2016). On the other hand, there are others who have a clear understanding of themselves, a sense of purpose in life and are able to articulate a personal vision (Berg, 2015), which motivates them in personal and professional domains. A meaningful and inspiring personal vision has been referred to by various names in religious and philosophical literature across cultures-one's North Star, Guiding Light, Calling, Noble Purpose, Dharma and Ideal Self, among others.

The scholarly exploration of the ideal self began primarily as a contrast to the actual or real self in forming a discrepancy (Higgins, 1987) or as one of the possible selves (Markus and Nurius, 1986). Theorizing has offered propositions on the constituent elements of the ideal self (Boyatzis and Akrivou, 2006). Organizational psychology research has alluded to an ideal work self in studies on identity development and change (Ashforth and Dukerich, 2001; Dutton et al., 2010; Ibarra, 1999). The common feature about the way in which the ideal self

(C) Richard Boyatzis and Udayan Dhar. Published in Journal of Management Development. Published by Emerald Publishing Limited. This article is published under the Creative Commons Attribution (CCBY 4.0) licence. Anyone may reproduce, distribute, translate and create derivative works of this article (for both commercial and non-commercial purposes), subject to full attribution to the original publication and authors. The full terms of this licence may be seen at http://creativecommons.org/licences/by/4.0/legalcode

The authors would like to thank Charalampos Mainemelis, Jean Bartunek and Kylie Rochford for help in reviewing drafts and refining our theory.

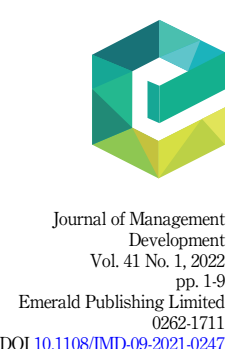

DOI 10.1108/JMD-09-2021-0247 
JMD

41,1

\section{2}

appears in management research is that it captures this construct at one moment in time. We believe that a static conceptualization of the ideal self does not adequately capture how it might change. People's aspirational work identities may change throughout their careers, and their personal identities may change throughout their life. A static model does not explain how changes in the components would lead to a revision of the ideal self. The field of identity change seeks to understand a part of the ideal self, but not enough theorizing on this larger concept exists to guide research.

Moreover, theories around the changes in identity (e.g. Ibarra, 1999) or changes in the reflected best self (RBS; Roberts et al., 2005) cannot be replicated in the context of the ideal self because the ideal self is conceptually distinct and more than either idea. The ideal self, as we conceptualize it, is different from identity because it (1) is aspirational and may include values that are aspirational as well, (2) provides linkages among various components of a person's current and desired future selves and (3) incorporates the notions of calling and sense of purpose that could be distinct from identity. The ideal self is also distinct from RBS, because the RBS is said to be in the territory between the ideal and real self, especially where the two converge (Roberts et al., 2005). The RBS is based upon experiences in the past, not on aspirations for the future.

The objective of this paper is to update, enhance and refine the Boyatzis and Akrivou's (2006) model and develop a temporal understanding of the dynamics of the ideal self. We examine how key factors such as a person's understanding of their purpose, values, operating philosophy, and personal and social identities trigger emergent changes in the ideal self. We also describe how the changes may be reinterpreted over one's life and career eras, based on new salient experiences and socialization. We conclude with a discussion on how this theory helps to integrate the construct of the ideal self in future research on intentional change.

\section{The emergence of the ideal self}

The self is a multi-faceted, dynamic cognitive structure containing all of a person's self-representations, such as personal characteristics, occupational and personal roles, activities, habits, group and organizational memberships, and demographic characteristics (Markus and Nurius, 1986). The self can be described both in terms of what one is at the present and in terms of the differences from the real self. Yet, the ideal self could also be independent from the real self, because a possible future self may function as a guide for future behavior, beyond its comparison to the real self (Higgins, 1987). Based on this understanding, we define the ideal self as a person's image of themselves in a desirable future life and work that one is hopeful about. A personal vision is a statement of the ideal self and its components and consequences. In this section, we will look into the psychological components of the ideal self and their relationships.

\section{Components of the ideal self}

The ideal self has been described as having components of one's purpose, personal values and philosophy, personal and social identity (Boyatzis and Akrivou, 2006). We review and refine these concepts in this section based on recent findings.

Purpose, meaning and calling. Purpose is a stable and generalized intention to accomplish something that is at once meaningful to the self and of consequence to the world beyond the self (Damon et al., 2003), while meaning is the sense made of, and significance felt regarding the nature of one's being and existence (Steger et al., 2009). A sense of purpose or meaning of work can be interpreted as something more than work as an instrument for pay or status. The related construct of calling is defined in relation to any work or social role that holds otheroriented values and goals as primary sources of motivation (Dik and Duffy, 2009). 
Since for many people, work is the focus of their most intense effort and energy (Blustein, 2008), change in professional identity toward a better fit with internal or external standards can therefore be a step towards an ideal self (Dutton et al., 2010).

While Ibarra's (1999) model of provisional selves or Pratt and Foreman's (2000) model of organizational adaptation focused on aligning the hoped-for self with external standards such as role models, we believe that internal standards expressed through one's purpose or meaning is the salient basis for the ideal self. In fact, an ideal self based on external standards, is the ought self, which describes a version of the ideal imposed by others, or by a person's desire to please others (Boyatzis and Akrivou, 2006). Imagining or visioning a self in the distant future can increase the search for meaning (Vazeou-Nieuwenhuis et al., 2017). Therefore, a sense of purpose, meaning or calling contributes to the articulation and conscious awareness of an ideal self by focusing a person's attention on their future desired self. It sifts through the myriad possibilities to those most salient to the person at the time.

Personal values and operating philosophy. Personal values have impact on a person's intentions and feelings across situations (Schwartz et al., 2010), and they help us evaluate if we are being a "good person" or in determining if we are living "a good life" (Haybron and Tiberius, 2012). Work values determine preferences for the type of work or work environment individuals would consider important (Dose, 1997), and will therefore relate to a person's aspirational professional identity. It has been theorized that each person has a philosophy of life that is used for making important decisions related to relationships, behaviors and goals (Schlegel et al., 2011). Such an operating philosophy is a way to determining value (Boyatzis et al., 2000) and forms a lens through which a person views and therefore evaluates events, people and activities. Ultimately, both values and operating philosophy help the individual winnow their plethora of possible selves down to a single ideal self.

Personal and social identities. Various aspects of identity feed into the ideal self. One is the personal, or self-identity, that describes the meaning individuals attach to themselves (Gecas, 1982), often linked to a person's core values. This aspect of identity is used by an individual in choices as to their goals, values and desires rather than as a member of a group. The other is a person's social identity, or identities that consist of a person's most salient and often aspirant social identifications. This involves aspiring to being like others in a specific group, and seeing things from the group's perspective (Stets and Burke, 2000; Tajfel, 1982), and also helps develop individual-level aspirations (Ostrove et al., 2011). Together, they form the identity components of the ideal self by helping the individual define who they wish to be and with whom they wish to be associated (Sluss and Ashforth, 2007). Similar to values, a sense of one's salient and aspirational personal and social identities will help a person to make choices among possible futures.

\section{The roles of prospection and hope}

Previous theorization on the ideal self emphasized the act of conjuring up an image of oneself in the future, because imagination is associated with mental stimulation (Boyatzis and Akrivou, 2006). We believe that the primary psychological mechanism here is simulation, with stimulation being the outcome; and it is in this context that we introduce the idea of prospection in our updated model. Prospection is the ability to pre-experience the future by simulating it in our minds (Gilbert and Wilson, 2007) and involves the representation and evaluation of possible futures (Bulley and Schacter, 2020). Prospection can lead to fantasies (Oettingen and Mayer, 2002) and sense-making (Vazeou-Nieuwenhuis et al., 2017). It involves a sifting through the many possible dreams of a person into those that fit into a coherent ideal self (Reay et al., 2017).

Studies in neuroscience (Denny et al., 2014; Jack et al., 2013a, b) that have focused on the neural correlates of imagining the future self have revealed the close relationship of what is 
JMD

41,1

4

meaningful in the present with what is aspirational for the future. Prospection or episodic future thinking (Seligman et al., 2013) is a plausible candidate contributor to affective forecasting, motivation in goal pursuit and the explicit evaluation of choice outcomes (Bulley and Schacter, 2020). In other words, it is the act of prospection that allows a person to conjure up a vision of their ideal self.

Forecasting is based on the real self. It takes into account past trends and present capabilities. It is an analytic task that uses the neural task positive network (Jack et al., 2013b). Prospection about a possible desired future uses the lateral visual cortex and part of the default mode network (DMN) (Jack et al., 2013a, b). Prospection has been linked to elements of the DMN (Seligman et al., 2013). Because these two neural networks suppress each other, forecasting or planning details will likely inhibit the ability to consider the possibilities, dream and/or create an ideal self.

Hope is a positive motivational state that is based on an interactively derived sense of successful agency and pathways (Snyder et al., 1991) and is an affective driver of the ideal self (Boyatzis and Akrivou, 2006; Higgins, 1987). As an emotional state, hope shapes, modifies and energizes the emerging ideal self. In relation to the ideal self, it has been related to career commitment, engagement, life satisfaction and organizational commitment (Berg, 2015; Buse and Bilimoria, 2014). Therefore, one can conceive of hope as a moderating variable in the relationship between prospection and the articulation of an ideal self.

\section{Temporal discontinuities in the ideal self}

Salient experiences in life and work will likely affect aspects of the person's values, identity, purpose or hope about future possibilities. Experiences such as childbirth (Malacrida and Boulton, 2012), role transitions (Ashforth and Dukerich, 2001) or even telecommuting (Thacher and Zhu, 2006) open new possibilities. When these experiences invoke reflection, it is likely that conscious awareness precedes changes in one's ideal self. While awareness of changes in components of the ideal self may happen gradually, each change may come into a person's consciousness in a moment of emergence (i.e. an epiphany or discovery) and may feel like a discontinuous leap (Boyatzis, 2008). It is therefore important to specify the underlying psycho-social mechanisms of such temporal discontinuities. Elaborating upon this aspect of individual-level change is an important extension of the previous model of the ideal self because it moves the theory from the static to the dynamic realm.

A person's sense of purpose or meaning (Kashdan and McKnight, 2009; Steger et al., 2009) and their personal or social identities (Ladge et al., 2012; Shepherd and Williams, 2018) may change with age as a result of the cumulative effect of salient experiences and their associated liminal periods (Ibarra and Petriglieri, 2010). A liminal period is a desirable, but not necessary condition for the formulation of a new ideal self. A promotion or a job loss itself may be enough to trigger conscious reflections and decisions about one's long-term professional aspirations.

Socialization, defined as a series of experiences to help someone learn the norms and values in an organization (Van Mannen and Schein, 1979) may also bring changes in a person's aspirations for the future and their sense of belonging (Sneed and Whitbourne, 2003) through self-reflection (Pratt et al., 2006). Membership in social identity groups reflects both meaning and belonging. Meaning is conveyed through values, norms and symbols. Belonging provides a vehicle for inclusion which helps with social comparison and differentiation from other possible social identity groups. A person's desire to be part of a social identity group encourages the values and behavior of the group being integrated into their own repertoire (Burke, 2006). Past socialization and key experiences can create lingering identities that can hold back change (Whittman, 2019). Changes can occur through negotiated adaptation, identity substitution or creation of an identity quite different from the earlier ones 
(Whittman, 2019). Several key experiences and socialization may occur simultaneously or in succession before a tipping point.

\section{The role of life and career stages or eras}

Time itself can be seen as a stage on which the drama of key experiences and socialization take place (Dutton et al., 2010). Classical theories by Erickson (1985) and Levinson (1978), reflected in the career realm by Super (1984) and Dalton and Thompson (1986), propose that a person progresses (or regresses) through life or career in a series of stages, with periods of transition between them. In contrast, Schein's (1978) sequence model and Driver's (1982) variation called spiral careers, were deemed appropriate for people in professions in which they change their specialty rather than jobs. More recent research on identity and the agespan have shown age-related differences appearing. These variations have been demonstrated in the realm of possible selves (Frazier et al., 2000), ideal selves (Dhar, 2021), values (Gouveia et al., 2015) and personality (Kitayama et al., 2020).

Reconstructing a coherent and meaningful ideal self from altered values, purpose and identity happens primarily in two ways. First, a new career/life era may change relationships and therefore reorder the salience of key experiences and socialization. We prefer the term "era" to reflect the protean and nonhierarchical nature of modern careers. Second, the nature of a new era may invoke a transformation in the interpretation of these experiences. For example, a person in their early career might interpret a promotion as affirmation of their job mastery. In mid-career, the same promotion may be seen as a sign of being valued and increase the salience of the inclusion in the social identity group the organization represents. At a late career era, the promotion may also raise questions about accepting it and think of ways to use it for other, possibly generative purposes. Ultimately, macro-career transitions may affect the ideal self and begin long before an actual role change (Ibarra and Barbulescu, 2010) as a sense of restlessness and seeking alternatives may begin.

In sum, career and life eras will likely mediate the emergence of a person's ideal self for each new era. Life and career eras become the longer time cycle, often seven plus or minus two years, for any possible changes to the ideal self. Within any life or career era, other key or salient experiences as well as socialization experiences will also occur on possibly briefer cycle times.

These changing experiences create an iterative process of change. It may feel like a rhythm but is more likely discontinuous in time between key events or realizations as well as the overall cycle periodicity as shown in Figure 1.

\section{Discussion}

Most of the identity literature has not addressed the ideal self or merely viewed it as a part of the discrepancy with the real self. The real self is often easier to notice and measure. The ideal self is more elusive. Our theory on the dynamics of the ideal self bring clarity to this construct and informs future studies on identity-related transitions. It brings attention to the individual's response to ongoing events that invite a change in the ideal self, adaptation (Whittman, 2019), reconciliation (Reay et al., 2017) or exploration of possibilities in the form of identity play (Ibarra and Petriglieri, 2010). "Playing with" an element of the ideal self, as a way to experiment with emergent feelings and cognition, offers identity researchers a window into the dynamics of growth.

Greater understanding the dynamics of the ideal self could come from specifying the type of salient experiences at home and work that help or hinder its emergence. Future studies should also look at the individual-level factors, such as personality, that determine the period and frequency of change in the ideal self. The ideal self could be used as an independent, dependent 
$\underset{41,1}{\mathrm{JMD}}$

6

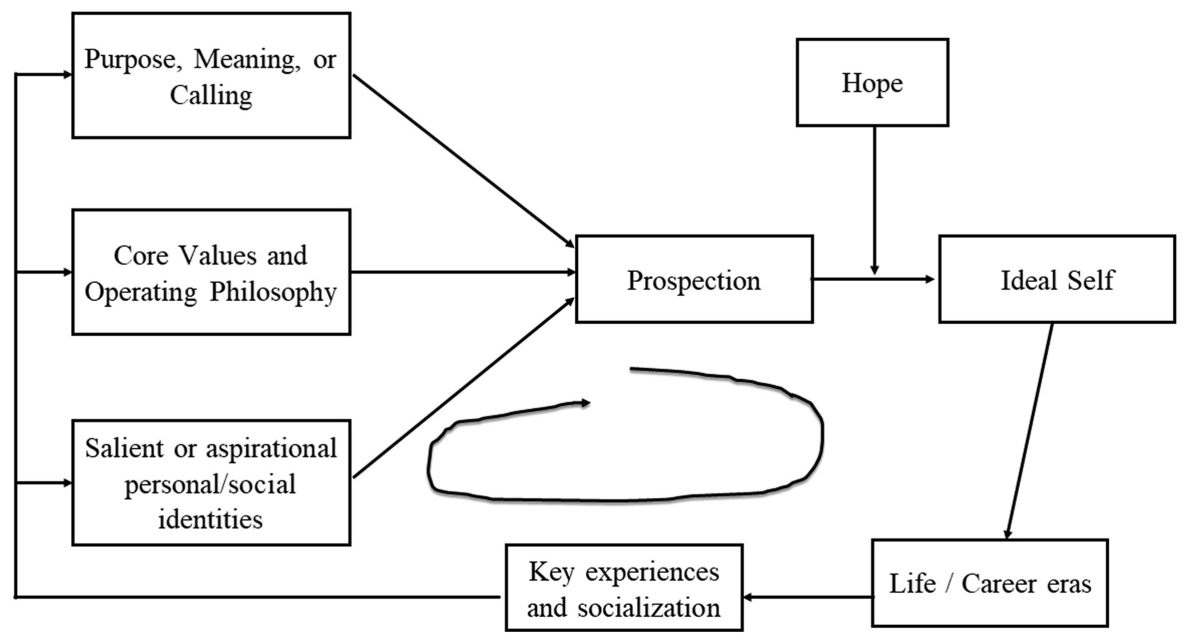

Figure 1.

The dynamics of the ideal self

or moderating variable and help to explain further variation in subjects' engagement or actual sustainability of learning or change.

Future research may also examine the role of time in understanding the changes in the ideal self. Specifically, instead of looking at changes in a person's aspirations and dreams over pre-determined stages, researchers could make use of subjective eras (i.e. studying what a career era would mean to an individual). Such a research design would examine the changes in the ideal self, a person's motivation and engagement in terms of both diversity in the modern workforce and the diversity of how work is conducted. Finally, since all processes affecting a person's ideal self exist in the context of a person's relationships (Boyatzis and Rochford, 2020) and culture (Kitayama et al., 2020), greater attention should be paid to these as potential moderators.

A theory of the dynamic ideal self can help practitioners diagnose their organizational culture on the extent to which it caters to the ideal self, and tailor their interventions more appropriately based on where people are in their life or career eras. The sequence of components in training, development and education programs could be changed to feature development and articulation of the ideal self sooner. Doing this at various times during a person's life and career would help them maintain an updated version of their ideal self and be less vulnerable to meaningless distractions. Being exposed to diverse people at work can help young adults make social comparisons and aid in their exploration of ideal self possibilities. Coaching, both individually, and in groups, could be used to help a person focus on the ideal self and understand how it changes over time.

\section{References}

Ashforth, B. and Dukerich, J. (2001), "Role transitions in organizational life: an identity-based", Academy of Management Review, Vol. 16 No. 4, p. 670.

Berg, J.L. (2015), "The impact of symbiotic visions on performance and a sense of personal accomplishment: increasing engagement and motivation through vision alignment", Frontiers in Psychology, Vol. 5, p. 1335, doi: 10.3389/fpsyg.2014.01335.

Blustein, D.L. (2008), "The role of work in psychological health and well-being: a conceptual, historical, and public policy perspective", American Psychologist, Vol. 63 No. 4, p. 228. 
Boyatzis, R.E. (2008), "Leadership development from a complexity perspective”, Consulting Psychology Journal: Practice and Research, Vol. 60 No. 4, pp. 298-313.

Boyatzis, R.E. and Akrivou, K. (2006), "The ideal self as the driver of intentional change", Journal of Management Development, Vol. 25 No. 7, pp. 624-642.

Boyatzis, R.E. and Rochford, K. (2020), "Relational climate in the workplace: dimensions, measurement, and validation", Frontiers in Psychology, Vol. 11, article 85, pp. 1-16.

Boyatzis, R.E., Murphy, A.J. and Wheeler, J.V. (2000), "Philosophy as a missing link between values and behavior", Psychological Reports, Vol. 86 No. 1, pp. 47-64.

Bulley, A. and Schacter, D.L. (2020), "Deliberating trade-offs with the future", Nature Human Behaviour, Vol. 4 No. 3, pp. 238-247.

Burke, P.J. (2006), “Identity change”, Social Psychology Quarterly, Vol. 69 No. 1, pp. 81-96.

Buse, K.R. and Bilimoria, D. (2014), "Personal vision: enhancing work engagement and the retention of women in the engineering profession", Frontiers in Psychology, Vol. 5, p. 1400.

Cates, J. (2015), “The meaninglessness epidemic - a 21st century disease?”, The Huffington Post, available at: https://www.huffingtonpost.co.uk/joanna-cates/the-meaninglessness-epide_b_6557760.html (accessed 24 August 2020).

Dalton, G. and Thompson, P. (1986), Novations: Strategies for Career Development, Scott Foresman, Glenview, IL.

Damon, W., Menon, J. and Cotton Bronk, K. (2003), "The development of purpose during adolescence", Applied Developmental Science, Vol. 7 No. 3, pp. 119-128.

Denny, B.T., Ochsner, K.N., Weber, J. and Wager, T.D. (2014), “Anticipatory brain activity predicts the success or failure of subsequent emotion regulation", Social Cognitive and Affective Neuroscience, Vol. 9 No. 4, pp. 403-411.

Dhar, U. (2021), "Managerial identity development across the age-spectrum from an ideal self and values perspective", The Journal of Management Development, Vol. 40 No. 6, pp. 574-583.

Dik, B.J. and Duffy, R.D. (2009), "Calling and vocation at work: definitions and prospects for research and practice", The Counseling Psychologist, Vol. 37 No. 3, pp. 424-450.

Dose, J.J. (1997), "Work values: an integrative framework and illustrative application to organizational socialization", Journal of Occupational and Organizational Psychology, Vol. 70 No. 3, pp. 219-240.

Driver, M.J. (1982), “Career concepts- A new approach to career research”, in Katz, R. (Ed.), Career Issues in Human Resource Management, Prentice-Hall, Englewood Cliffs, NJ.

Dutton, J.E., Roberts, L.M. and Bednar, J. (2010), "Pathways for positive identity construction at work: four types of positive identity and the building of social resources", Academy of Management Review, Vol. 35 No. 2, pp. 265-293.

Erikson, E.H. (1985), The Life Cycle Completed: A Review, W.W. Norton, NY.

Frazier, L.D., Hooker, K., Johnson, P.M. and Kaus, C.R. (2000), "Continuity and change in possible selves in later life: a 5-year longitudinal study", Basic and Applied Social Psychology, Vol. 22 No. 3, pp. 237-243.

Gecas, V. (1982), “The self-concept”, Annual Review of Sociology, Vol. 8, pp. 1-33.

Gibson, C.B., Dunlop, P.D. and Raghav, S. (2020), "Navigating identities in global work: antecedents and consequences of intrapersonal identity conflict", Human Relations, Vol. 74 No. 4, 0018726719895314.

Gilbert, D.T. and Wilson, T.D. (2007), "Prospection: experiencing the future", Science, Vol. 317 No. 5843, pp. 1351-1354.

Gouveia, V.V., Vione, K.C., Milfont, T.L. and Fischer, R. (2015), "Patterns of value change during the life span: some evidence from a functional approach to values", Personality and Social Psychology Bulletin, Vol. 41 No. 9, pp. 1276-1290. 
JMD

41,1

8

Harter, J. (2020), "Historic drop in employee engagement follows record rise", Gallup, available at: https://www.gallup.com/workplace/313313/historic-drop-employee-engagement-follows-recordrise.aspx (accessed 01 April 2020).

Haybron, D.M. and Tiberius, V. (2012), "Normative foundations for well-being policy", Papers on Economics and Evolution. No. 1202, Max Planck Institute of Economics, Jena.

Higgins, E.T. (1987), "Self-discrepancy: a theory relating self and affect", Psychological Review, Vol. 94 No. 3, pp. 319-340.

Ibarra, H. (1999), "Provisional selves: experimenting with image and identity in professional adaptation”, Administrative Science Quarterly, Vol. 44 No. 4, pp. 764-791.

Ibarra, H. and Barbulescu, R. (2010), "Identity as narrative: prevalence, effectiveness, and consequences of narrative identity work in macro work role transitions", Academy of Management Review, Vol. 35 No. 1, pp. 135-154.

Ibarra, H. and Petriglieri, J.L. (2010), "Identity work and play", Journal of Organizational Change Management, Vol. 23 No. 1, pp. 10-25.

Jack, A.I., Boyatzis, R.E., Khawaja, M.S., Passarelli, A.M. and Leckie, R.L. (2013a), "Visioning in the brain: an fMRI study of inspirational coaching and mentoring", Social Neuroscience, Vol. 8 No. 4, pp. 369-384.

Jack, A.I., Dawson, A.J., Begany, K.L., Leckie, R.L., Barry, K.P., Ciccia, A.H. and Snyder, A.Z. (2013b), "fMRI reveals reciprocal inhibition between social and physical cognitive domains", NeuroImage, Vol. 66, pp. 385-401.

Kashdan, T.B. and McKnight, P.E. (2009), "Origins of purpose in life: refining our understanding of a life well lived”, Psihologijske teme, Vol. 18 No. 2, pp. 303-313.

Kitayama, S., Berg, M.K. and Chopik, W.J. (2020), "Culture and well-being in late adulthood: theory and evidence", American Psychologist, Vol. 75 No. 4, p. 567.

Ladge, J.J., Clair, J.A. and Greenberg, D. (2012), "Cross-domain identity transition during liminal periods: constructing multiple selves as professional and mother during pregnancy", Academy of Management Journal, Vol. 55 No. 6, pp. 1449-1471.

Levinson, D.J. (1978) Darrow. CN, Klein, EB, Levinson, MH, and McKee, B, The Seasons of a Man's Life, Knopf, NY.

Malacrida, C. and Boulton, T. (2012), "Women's perceptions of childbirth 'choices' competing discourses of motherhood, sexuality, and selflessness", Gender and Society, Vol. 26 No. 5, pp. 748-772.

Markus, H. and Nurius, P. (1986), "Possible selves", American Psychologist, Vol. 41 No. 9, p. 954.

Oettingen, G. and Mayer, D. (2002), "The motivating function of thinking about the future: expectations versus fantasies", Journal of Personality and Social Psychology, Vol. 83 No. 5, p. 1198.

Ostrove, J.M., Stewart, A.J. and Curtin, N.L. (2011), "Social class and belonging: implications for graduate students' career aspirations", The Journal of Higher Education, Vol. 82 No. 6, pp. 748-774.

Pratt, M.G. and Foreman, P.O. (2000), "Classifying managerial responses to multiple organizational identities”, Academy of Management Review, Vol. 25, pp. 18-42.

Pratt, M.G., Rockmann, K.W. and Kaufmann, J.B. (2006), "Constructing professional identity: the role of work and identity learning cycles in the customization of identity among medical residents", Academy of Management Journal, Vol. 49 No. 2, pp. 235-262.

Reay, T., Goodrick, E., Waldorff, S.B. and Casebeer, A. (2017), "Getting leopards to change their spots: Co-creating a new professional role identity", Academy of Management Journal, Vol. 60 No. 3, pp. 1043-1070.

Roberts, L.M., Dutton, J.E., Spreitzer, G.M., Heaphy, E.D. and Quinn, R.E. (2005), "Composing the reflected best-self portrait: building pathways for becoming extraordinary in work organizations", Academy of Management Review, Vol. 30 No. 4, pp. 712-736. 
Schein, E.H. (1978), Career Dynamics: Matching Individual and Organizational Needs, Addison Wesley Publishing Company, Reading, Massachusetts, p. 6834.

Schlegel, R.J., Hicks, J.A., King, L.A. and Arndt, J. (2011), "Feeling like you know who you are: perceived true self-knowledge and meaning in life", Personality and Social Psychology Bulletin, Vol. 37 No. 6, pp. 745-756.

Schwartz, S.H., Caprara, G.V. and Vecchione, M. (2010), "Basic personal values, core political values, and voting: a longitudinal analysis", Political Psychology, Vol. 31 No. 3, pp. 421-452.

Seligman, M.E., Railton, P., Baumeister, R.F. and Sripada, C. (2013), "Navigating into the future or driven by the past", Perspectives on Psychological Science, Vol. 8 No. 2, pp. 119-141.

Shepherd, D.A. and Williams, T.A. (2018), "Hitting rock bottom after joblessness: bouncing back to create a new positive work identity", Academy of Management Review, Vol. 43 No. 1, pp. 28-49.

Sluss, D.M. and Ashforth, B.E. (2007), "Relational identity and identification: defining ourselves through work relationships", Academy of Management Review, Vol. 32 No. 1, pp. 9-32.

Sneed, J.R. and Whitbourne, S.K. (2003), "Identity processing and self-consciousness in middle and later adulthood", The Journals of Gerontology Series B: Psychological Sciences and Social Sciences, Vol. 58 No. 6, pp. 313-319.

Snyder, C.R., Harris, C., Anderson, J.R., Holleran, S.A., Irving, L.M., Sigmon, S.T., Yoshinab, U., Gibb, J., Langelle, C. and Harney, P. (1991), "The will and the ways: development and validation of an individual-differences measure of hope", Journal of Personality and Social Psychology, Vol. 60 No. 4 , p. 570.

Steger, M.F., Oishi, S. and Kashdan, T.B. (2009), "Meaning in life across the life span: levels and correlates of meaning in life from emerging adulthood to older adulthood", The Journal of Positive Psychology, Vol. 4 No. 1, pp. 43-52.

Stets, J.E. and Burke, P.J. (2000), "Identity theory and social identity theory", Social Psychology Quarterly, Vol. 63 No. 3, pp. 224-237.

Stolzer, J.M. (2016), "The meteoric rise of mental illness in America and implications for other countries", The European Journal of Counselling Psychology, Vol. 4 No. 2, pp. 228-246.

Super, D.E. (1984), "Career and life development”, in Brown, D. and Brooks, L. (Eds), Career Choice and Development, Jossey-Bass, San Francisco.

Tajfel, H. (1982), "Social psychology of intergroup relations", Annual Review of Psychology, Vol. 33 No. 1, pp. 1-39.

Van Mannen, J. and Schein, E. (1979), “Toward a theory of organizational socialization”, Annual Review of Research in Organizational Behavior, Vol. 1, pp. 209-264.

Vazeou-Nieuwenhuis, A., Orehek, E. and Scheier, M.F. (2017), "The meaning of action: do selfregulatory processes contribute to a purposeful life?", Personality and Individual Differences, Vol. 116, pp. 115-122.

Whittman, S. (2019), "Lingering identities", Academy of Management Review, Vol. 44 No. 4, pp. 724-745.

\section{Corresponding author}

Richard Boyatzis can be contacted at: richard.boyatzis@case.edu

For instructions on how to order reprints of this article, please visit our website:

www.emeraldgrouppublishing.com/licensing/reprints.htm

Or contact us for further details: permissions@emeraldinsight.com 